\title{
Evaluation of the remote lower protective seam mining for coal mine gas control: A typical case study from the Zhuxianzhuang Coal Mine, Huaibei Coalfield, China
}

Kan Jin ${ }^{a, b, c}$, Yuanping Cheng ${ }^{a, b, c, *}$, Wei Wanga,b,c, Haibo Liua, ${ }^{a, b, c}$, Zhengdong Liua, ${ }^{a, b, c}$, Hao Zhang ${ }^{a, b, c}$

a Key Laboratory of Coal Methane and Fire Control, Ministry of Education, China University of Mining and Technology, Xuzhou, Jiangsu 221116, China

${ }^{b}$ National Engineering Research Center for Coal and Gas Control, China University of Mining and Technology, Xuzhou, Jiangsu 221116, China

c School of Safety Engineering, China University of Mining and Technology, Xuzhou, Jiangsu 221116, China

* Corresponding author at: National Engineering Research Center for Coal and Gas Control, China University of Mining and Technology, Xuzhou, Jiangsu 221116, China. Tel.: +86 516 83885948; fax: +8651683995097.

E-mail addresses: ypc620924@gmail.com (Y. Cheng), jinkan@outlook.com (K. Jin).

\section{Abstract}

The protective seam mining technology is the most effective and economical method in realizing the safe mining of outburst-prone coal seams. To study the effects of remote lower protective seam mining on coal mine gas control, a typical case (average layer spacing: $78 \mathrm{~m}$ ) taken from the Zhuxianzhuang Coal Mine was investigated by a comprehensive evaluation through numerical simulation, gas extraction data statistics, residual gas pressure/content measurements and recovering gas emission analysis. The results indicate that after the recovery of the protective seam, the unloading effects could lead to a maximum expansion deformation rate of the protected seam by $33.4 \%$, which remarkably increases the permeability of the coal seam by 4320 times. Combining with the pressure-relief gas extraction methods, considerable amount of the gas (about $78.58 \%$ ) was extracted from the protected seam, resulting in the maximum residual gas pressure and content of $0.26 \mathrm{MPa}$ and $4.29 \mathrm{~m}^{3} / \mathrm{t}$ respectively, which indicate that the outburst risk has been completely eliminated. Additionally, among the gas extraction methods, the penetrating borehole extraction presents the best drainage effect, accounting for $42.58 \%-55.09 \%$ of the total extracted pressure-relief gas. The effect of the surface wells extraction is closely related to the number of wells and whether the wells can work properly or not. However, the effect of interception boreholes extraction is poor and the extracted amount is almost negligible. Moreover, a protected range extension phenomenon is noticed, which demonstrate that the protected area generated by the protective seam mining is larger than that of the theoretical predicted one, and thus a further study is needed.

Keywords: Protective seam mining; Gas control; Pressure-relief; Gas extraction. 


\section{Introduction}

Coal mine gas (CMG) is a self-generated and self-reservoir gas generated in the coalification process and accumulated in coal seams (Bao et al., 2016; Bustin and Clarkson, 1998; Tao et al., 2007). The amount of CMG contained in reservoirs depends on a number of factors, such as coal rank, burial depth, rock type of the roof and floor, local geologic anomalies and tectonic pressures, resulting in various gas content ranging from $<1 \mathrm{~m}^{3} / \mathrm{t}$ to over $40 \mathrm{~m}^{3} / \mathrm{t}$ (Jiang et al., 2011; Kissell, 2006; Li et al., 2011; Su et al., 2005). CMG has always been considered as a major mine hazard since the early $19^{\text {th }}$ century when the first documented coal and gas outburst occurred in France in 1834 (Flores, 1998). To avoid the outburst risk in mining activities, several coal-mining countries, e.g. France, Belgium and Japan, forbade the mining of the outburst-prone coal seams in the 1970s. However, in order to meet China's energy demand, even the outburst-prone coal seams still need to be mined (Lu et al., 2015a) and which makes this country the most serious outburst risk menaced region all around the world, almost one half of the world's ever recorded coal and gas outbursts occurred in China (Jiang et al., 2015a; Lama and Saghafi, 2002; Zhao et al., 2016; Zhou et al., 2014).

Despite the fact that the mechanisms causing coal and gas outbursts are still confusing the scientists (Beamish and Crosdale, 1998; Karacan et al., 2011; Lu et al., 2015b; Noack, 1998; Shepherd et al., 1981), generally accepted theory considers that the gas drainage prior to the mining (namely gas pre-drainage) is the most effective method in reducing or eliminating the outburst risk (Cheng and Yu, 2007; Creedy and Tilley, 2003; Noack, 1998; Zhou et al., 2015a). Cheng and Yu (2007) and Karacan et al (2011) indicate that most Chinese coal strata underwent several strong tectonic movements after their formation and the original construction of the coal seams was ruined, as a result the coals became structurally complicated, soft and highly impermeable for gas flow. Therefore, gas drainage from virgin outburst-prone coal seams is very difficult and the main feasible CMG drainage principles in China should be focused on the techniques of pre-mining of protective seam, surface well CMG recovery and underground gas pre-drainage (Lu et al., 2014; Zhou et al., 2015a). Among them, the protective seam mining technology combined with the pressure-relief gas 
extraction have been considered as the most effective and economical measure in realizing the safe mining of the outburst-prone coal seams (Cheng et al., 2010; Wang et al., 2013b).

The protective seam mining technology originated from France and was imported into China in 1958, but it was not widely applied until the first decade of this century (Wang et al., 2013b). Under coal seam group conditions, the protective seams are usually the coal seams with no or lower outburst-prone risks that would be mined firstly. The protected seams are the coal seams with higher gas pressure/content and outburst prone which locate tens of meters (within the zone influenced by protective seam mining activities) above or beneath the protective seam (Brauner, 1994; Li et al., 2014). After the mining of the protective seams, the geologic stress of the protected seam will be unloaded, which introducing cracks or bed-parallel fractures into the coal seams and adjacent rock layers. As a result, the permeability of the protected seams and their surrounding rocks will be significantly improved (Chen et al., 2013; Lu et al., 2016; Wang et al., 2013c; Zhou et al., 2015b), and the CMG storing in the protected seams begins to desorb and subsequently flows into the protective seam working face through the interlayer fissures (Aguado and Nicieza, 2007; Noack, 1998). At that moment, combining with a well-designed pressure-relief gas extraction measure the gas pressure/content of the protected seams can be significantly reduced and the outburst prone can be completely eliminated as well. Afterwards the mining of the protected seams will become much safer (Cheng et al., 2010; Wang et al., 2014).

To gain some nature of the effects of protective seam mining on coal mine gas control, a vast amount of work have been conducted. Yang et al (2011a) and Yang et al (2011b, 2011c) systematically investigated the stress distribution, strata deformation and permeability evolution during the mining of protective seams, indicating some universal regulations for CMG flow characteristics with time and space which providing general guidance for coal mine gas control. Wang et al (2015b) investigated the influence of section coal pillar width on the pressure-relief effects, recommending that the pillar width should be less than $5 \mathrm{~m}$ so that the protected seam working faces can obtain continuous pressure-relief effects. Liu et al (2009a) and Liu et al (2014) studied the pressure relief and deformation effects after the mining of an extra-thin protective coal seam. Zhang et al (2015a) proposed a new method for evaluating the pressure-relief effects based on surface gas vent hole extraction data. Li (2014) 
reported an artificial protective coal seam mining technology during thick single coal seam recovery, which using hydraulic mining equipment to mine a thin sub-layer as protective coal seam in order to achieve a self-protection. Studies on the application of protective seam mining demonstrate that although the pressure-relief properties are strongly affected by the coal seam thickness, working face layout, layer spacing, roof/floor structures et. al (Yang et al., 2015), this method still can achieve considerable effects (permeability of the protected seams increasing by hundreds to thousands of times, enhanced gas extraction of the CMG and improved mining safety) in almost all of the research areas (Cheng et al., 2004; Tu et al., 2007; Wang et al., 2008; Yuan, 2003).

However, with continuous extending of the mining depth, the traditional protective seam mining technology gradually meet with new challenges which perform as that it becomes more and more difficult to find a no or low outburst-prone coal seam in the same coal seam group whose layer spacing between each other is close $(20 \mathrm{~m}-50 \mathrm{~m})$. Therefore, the applications of the remote protective seam mining seem to be of great significance for deep coal mine gas control. Thakur (2006) indicated that the gas emission space may extend to $270 \mathrm{ft}(82.3 \mathrm{~m})$ below the coal seam being mined and $1000 \mathrm{ft}(304.8 \mathrm{~m})$ above it, which laid the foundation of remote protective seam mining. Song et al (2009) and Liu et al (2010) discussed the possibility of remote protected seam mining (layer spacing: $150 \mathrm{~m}$ and $129 \mathrm{~m}$ respectively) based on simulated material scale modeling and numerical simulation. The follow-up field studies from Liu et al. (2013) confirmed that under certain geological situation it is feasible for the protected seams to get sufficient pressure-relief effects even under such a long distance. Liu et al (2011) studied the deformation and fissure development characteristics after a remote double protected seams mining (layer spacing: $78.2 \mathrm{~m}$ ). Li et al (2014) investigated the field permeability evolution progress after the remote protective seam mining (maximum layer spacing: $54.1 \mathrm{~m}$ ), indicating the relationship between the permeability and geostress variation.

All of the studies listed above achieved sufficient pressure-relief effects and the outburst-prone of the protected seams was completely eliminated. However, these studies were conducted either based on a horizontal laid coal seam or a thin protected seam (maximum thickness: $6.42 \mathrm{~m}$ ), while the strata lithologies between the protective and 
protected seams are mainly composed of soft rocks such as mudstone and oil shale. Therefore, a case with a certain dip angle, thick protected seam and hard rocks composed interlayer is still of significant engineering meaning, as well as the systematical investigation of the whole protective seam mining procedure from design, execution to effect assessment.

This article takes the protective seam mining practice in the Zhuxianzhuang Coal Mine, Huaibei Coalfield as a typical case, the effects of remote lower protective seam mining technology (average layer spacing: 78m) for coal mine gas control were comprehensively evaluated through the combination application of numerical simulation, gas extraction data statistics, residual gas pressure/content measurements and recovering gas emission analysis.

\section{Geological Background}

\subsection{Regional geology}

Huaibei Coalfield is located in the northern Anhui Province of China, which is one of the major coalfields in this country, with 23 active underground coal mines. The main coal-bearing layer of the coalfield belongs to the Carboniferous-Permian system (Guo et al., 2014; Jin et al., 2015; Zheng et al., 2008).

The Zhuxianzhuang Coal Mine are located in the eastern region of the Huaibei Coalfield, covering an area of $26.3 \mathrm{~km}^{2}$ (Fig. 1), the main commercial seams of the mine is the No. 8 and No. 10 coal seams. The F10 Fault mainly divides the Zhuxianzhuang Coalfield into two geological units (namely northern and southern flanks), while the gas occurrence characteristics in these two flanks are entirely different. Coal seams in the northern flank lie in a shallow buried depth with surrounded outcrop and developed internal small open faults. Furthermore the existence of F10 Fault also efficiently prevent the migration of CMG from deep to shallow, thus the CMG preservation condition is poor which results in a low gas pressure and content. However, in the southern flanks where the study area of this article is focused on, the depth of the coal seams is deeper and the tectonic stress is much more centralized. Besides, the gas pool in this flank can receive supply from the even deeper coals. Consequently, the gas pressure, content and the risk of outburst in the southern flank are much more serious than the northern one.

[FIGURE 1] 


\subsection{Coal mine gas occurrence}

The gas pressure and gas content are both important indicators in the evaluation of outburst-prone risks of the coal seams (Diamond and Schatzel, 1998; Wang et al., 2012). Generally, a coal seam with a gas pressure greater than $0.74 \mathrm{MPa}$ or a gas content greater than $8 \mathrm{~m}^{3} / \mathrm{t}$ is considered to have the potential of initiating an outburst (SAWS, 2009; Yu and Cheng, 2012). The measurement results of the gas pressure and content in the II3 District, Zhuxianzhuang Coal Mine are shown in Fig. 2 while the proximate analyses and adsorption constants parameters of the coal seams are list in Table 1. Results indicate that the maximum gas pressure of the No. 8 and No. 10 coal seam are 4.10MPa and 0.61MPa respectively, while the maximum gas content of the coal seams are $11.49 \mathrm{~m}^{3} / \mathrm{t}$ and $5.60 \mathrm{~m}^{3} / \mathrm{t}$, respectively. Therefore, comparing with the No. 10 coal seam, the No. 8 coal seam is much gassier and more serious in outburst prone, which urgently call for technical means to eliminate the outburst risks before mining.

[FIGURE 2]

[TABLE 1]

\section{Numerical simulation of the remote lower protective seam mining}

\subsection{Design of protective seam mining}

Considering the CMG occurrence characteristics and the potential outburst risks of the II3 District, the No. 10 coal seam was chosen as the protective seam that would be mined firstly, then the overlying No. 8 coal seam can receive protection effects and the outburst prone could be eliminated. However, the majority of the successful protective seam mining cases in the past few years were brought into practice in the coal mines whose layer spacing between protective and protected seams are usually 20m-50m (Jiang et al., 2015b; Liu et al., 2009a; Wu et al., 2011). However, according to the generalized stratigraphy of the II3 District (Fig. 3), the layer spacing between No. 10 coal seam (protective seam) and No. 8 coal seam (protected seam) ranges from $70 \mathrm{~m}$ to $85 \mathrm{~m}$ ( $78 \mathrm{~m}$ in average), indicating a remote lower protective seam mining. Therefore, the mining design of this district should make appropriate adjustments when compared to that of the ordinary ones:

[FIGURE 3] 
1) Continuous mining of protective seam's working faces. Take the II832, II1034 and II1036 working faces of the II3 District as examples (diagrammatic sketch is shown in Fig. 4, detailed parameters of the working faces are listed in Table 2). As the layer spacing between No. 8 and No. 10 coal seam is indeed far off, if only mining the II1034 working face then the coal mass in the belt conveyor roadway side of the corresponding 11832 protected working face will not be able to get effective protection due to the presence of the pressure-relief angle (Fig. 5). However, with the design of continuous mining of the protective seam's working faces in tendency, namely mining the II1034 and II1036 working face to jointly protect the overlying No. 8 coal seam, the whole 11832 working face can be under protection.

[FIGURE 4]

[TABLE 2]

[FIGURE 5]

Additionally, the successful application of this method requires the width of the section coal pillars to be thin enough (usually reserved for about $4 \mathrm{~m}$ ), which allows the coal pillar between the II1034 and II1036 working faces to be squeezed after the recovery. Thus, the space for the unloading of overlying coal/rock mass can be provided and the complete pressure-relief effects for the protected seam working faces can be achieved.

2) Working level adjustment. Still affected by the pressure-relief angle, if the mining procedure of the II3 District's No. 10 coal seam is in accordance with the originally designed elevation $(-435 m \sim-680 m)$. Then the deep mining area of the No. 8 coal seam would fail to receive full protection (Fig. 5). In order to protect the deepest working face of the No. 8 coal seam in this district, an assistant working level should be set up (Cheng et al., 2015) which allows the mining depth of the No. 10 coal seam to descend by $80 \mathrm{~m}$, so that the overall region of the No. 8 coal seam in II3 District can be protected.

\subsection{Numerical model setting}

To investigate the stress unloading effects of the protected seam, the FLAC ${ }^{3 \mathrm{D}}$ software was used for calculating the stress and expansion deformation distribution after the recovery of the protective seam (Kong et al., 2014; Li et al., 2015). Based on the stratigraphy condition of the II3 District (Fig. 3), the numerical model was constructed to include all the major coal seams in the coal measure strata. The model covers an area of $368 \mathrm{~m} \times 420 \mathrm{~m}, 387.8 \mathrm{~m}$ in 
height and $23^{\circ}$ in angle of inclination. To simulate the load of the $230 \mathrm{~m}$ overburden, a compressive stress of $5 \mathrm{MPa}$ was imposed on the top of the model. Fig. 6 shows the 3D geometry and boundary conditions of the model. The Mohr-Coulomb failure criterion was selected for the simulation. The initial properties of the rock mass used in the simulation are listed in Table 3, which were determined based on the typical values cited from the geological prospecting report of the Zhuxianzhuang Coal Mine (parameters were all tested by the Mechanics Laboratory of the Anhui University of Science \& Technology).

[FIGURE 6]

[TABLE 3]

The stress and displacement variations of the rock formation after each excavation cycle were recorded by monitoring lines set in the roof and floor of the No. 8 coal seam respectively. In addition, five sections (namely section along the wind roadway, section along the belt conveyor roadway, central section of the 11832 working face, cross-section along the theoretic unloading boundary and the central section of the not protected area) were selected to perform an illustration of the protection effect.

\subsection{Simulation results and analysis}

\subsubsection{Stress variation of the protected seam}

After the mining of the protective seam, the overlying coal/rock mass above the middle part of the working face would transfer from a triaxial compression situation to the condition of expansion deformation, caving to the direction of mining goaf under gravity and generating the so-called unloading deformation (Guo and Xu, 2016; Krause and Skiba, 2014; Liu and Cheng, 2015; Liu et al., 2013). However, around the working face, a certain stress concentration area will be formed which will lead to a weak protective result.

According to simulation results (Fig. 7a and Fig. 7b), the closer to the open-off cut roadway of the 11832 working face, the less magnitude of stress unloading will be; at the same cross section, the coal mass near the wind roadway seems to have a less stress unloading magnitude than the coal near the belt conveyor roadway, indicating that the arrangement of protective seam working face and its spatial relationship with the protected seam will have significant impact on the protection effects. In addition, since the coal pillar width between the working faces is suitable, after the recovery of the protective seam, the 
coal pillar seems to be compressed to destruction so that the unloading effect of overlying No. 8 coal seam is not affected. Moreover, the monitoring data demonstrated that the unloading effect has led to a significant displacement of the overlying coal/rock mass. The displacement of the 11832 working face is $334.55 \mathrm{~mm}-761.2 \mathrm{~mm}$, and the maximum subsidence appears in the belt conveyor roadway side of the central section of the 11832 working face.

\section{[FIGURE 7]}

\subsubsection{Expansion deformation of the protected seam}

Generally accepted theory considers the expansion deformation rate of the protected seam as the most important evaluation index of the protection effects (Cheng et al., 2010; Yu and Cheng, 2012). The better expansion deformation will lead to a better development of cracks and fractures, thus the permeability increase of coal seam will be more obvious (Liu et al., 2009b; Zhang et al., 2015b). Since the geological conditions of the protective layer are various, the expansion deformation generated by different kinds of protective seams recovery will not be the same. However, it is widely accepted that when the expansion deformation rate is greater than $3 \%$ (SAWS, 2008, 2009), the protected seam will receive enough effects of pressure-relief and permeability increase.

Fig. 7c and Fig. 7d illustrate the expansion deformation conditions of No. 8 coal seam after the mining of the protective seam. Similar to the stress-unloading situation, the closer to the open-off cut roadway, the smaller the expansion deformation of the protected seam will be. Inside the theoretic unloading boundary causing by the mining of the II1034 and II1036 working faces, the expansion deformation rate of the II832 working face is mostly larger than the critical value of $3 \%$ (maximum reaches $11.43 \%$ ), which means that this area is located in the fully unloading zone and the protection effect is well. Nevertheless, outside the theoretic unloading boundary, most of the coal mass suffers a compression deformation, indicating that this area is located in the bracing stress zone produced by the protective seam mining and without feasible technical measures, this stress concentration area may face an outburst potential when the mining engineering approaches.

Near the theoretic unloading boundary, the coal mass is located in a transitional zone between the compression deformation zone and the fully unloading zone. The stress of the 
coal seam in this transitional zone is lower than that of the original stress, and the coal seam also exhibits expansion and deformation to some extent which result in a certain pressure-relief effect. However, the expansion deformation rate of this zone is overall around $3 \%$, therefore the effect of pressure-relief and permeability increase is lower than that of the coal in the fully unloading zone.

In a word, after the mining of protective seam, the unloading effect of the II832 working face is well overall. However, influenced by the spatial relationship between the protective seam and protected seam, there is a section of coal whose length is about $60 \mathrm{~m}-80 \mathrm{~m}$ from the open-off cut roadway which located in an insufficient unloading zone (some areas are even in a stress concentration zone). When the mining activities enter this section, it is strongly recommended to strengthen the coal and gas outburst prediction work for the sake of ensuring the safety production.

\section{Evaluation of pressure-relief gas extraction}

\subsection{Scheme of pressure-relief gas extraction}

During the mining of the II1034 working face, the actual expansion deformation rate as well as the permeability variation of the No. 8 coal seam were both measured from the II832 bed plate tunnel. The measurement of the expansion deformation rate was based on the displacement contrast method described by Wang et al (2015a) and Liu et al (2011), the results indicate that the expansive deformation of the protected seam is $89.4 \mathrm{~mm}-414.8 \mathrm{~mm}$ and the corresponding maximum expansion deformation rate reaches $33.4 \%$, which is far greater than the critical value of $3 \%$ and also larger than the numerical simulated one.

The permeability of the protected seam was calculated based on the borehole radial gas flow method proposed by Zhou and Lin (1997). Firstly, drill a borehole perpendicular to the coal seam which penetrates the coal seam until its roof or floor, and measure the gas content of the coal seam using a USBM direct method (Diamond and Schatzel, 1998). Secondly, seal the hole and install the pressure gauge, flow meter and valve (keep the valve open at this moment). When the sealing material in the borehole was solidified, close the valve and wait for the pressure getting stable, then record the pressure value as the gas pressure of the coal seam. Thirdly, open the valve and record the quantity of flow using the flow meter for 
several days. Finally, summarize the data and calculate the permeability. The schematic diagram of the measurement method is shown in Fig. 8.

[FIGURE 8]

The field measurement results of the No. 8 coal seam's permeability indicate that the permeability of the protected seam increased from $0.1098 \mathrm{~m}^{2}$ to $474.32 \mathrm{~m}^{2}$, which is 4320 times greater than the original permeability. Therefore, after the recovery of the protective seam, the protected seam obtained sufficient unloading effects and thus provided good conditions for the pressure-relief gas extraction.

The overall gas extraction pattern of the II3 District during the protective seam mining can be summarized as Fig. 9, the pertinent parameters are comprehensively determined based on the results of numerical simulations, field experiments and accumulated experiences in this coalfield. To improve the gas control effect of the protected seam mining and completely eliminate the outburst risk of the protected seam, pressure-relief gas extraction measures should be taken into application during the mining of protective seam, and the main method is to drill net-like penetrating boreholes from the bed plate tunnel of the protected seam (Cheng et al., 2010; Wang et al., 2014). Restricted by the underground engineering conditions (Fig. 9a), the II1034 working face is not correspondingly arranged with 11832 working face in strike direction. Considering the influence of the pressure-relief angle, there will be a section of coal from the II832's open-off cut roadway whose length is about $160 \mathrm{~m}$ located beyond the theoretic unloading boundary (Fig. 9e). For this not protected area, a dense borehole gas extraction method was adopted to fully eliminate the outburst risk of the coal seam. Moreover, surface wells were also applied to provide an auxiliary gas drainage. Two surface wells (spacing is $300 \mathrm{~m}$ ) were arranged above the II1034 working face, and five more surface wells (spacing is $120 \mathrm{~m}$ ) were arranged above the II1036 working face (Fig. 9e).

\section{[FIGURE 9]}

For the sake of preventing the pressure-relief gas from flowing into the protective seam working faces, interception boreholes from No. 10 coal seam working face were utilized to assist the gas drainage through the fracture channels between the protective seam and protected seam (Liu and Cheng, 2015), avoiding the risk introduced by gas concentration 
overrun.

Additionally, the gas emission during the mining of the protective working face was mainly solved by the combining use of ventilation, strike high level boreholes and goaf burying pipes (Fig. 9b and Fig. 9c). Also the surface wells can assist the extraction of goaf gas.

\subsection{Effects of gas extraction}

\subsubsection{Statistics of pressure-relief gas extraction}

The statistics of the gas extraction during the mining of the II1034 working face (Fig. 10a) indicate that the pressure-relief gas is mainly extracted by the penetrating boreholes, surface wells and interception boreholes. Among them, the extraction amount through the bed plate tunnel is the largest and the flow rate is the most stable $\left(31.61 \mathrm{~m}^{3} / \mathrm{min}\right.$ on maximum, $9.95 \mathrm{~m}^{3} / \mathrm{min}$ on average). While the amount of the surface wells is relatively large in the initial stage (maximum reaches $16.71 \mathrm{~m}^{3} / \mathrm{min}$ ) and then decay rapidly, indicating that the well in the middle position of the II1034 working face do not play its due role possibly because of collapse or other reasons. Furthermore, the gas extraction amount of the interception boreholes in the initial stage is also noticeable (maximum reaches $9.67 \mathrm{~m}^{3} / \mathrm{min}$ ) but decay rapidly, its contribution to the whole pressure-relief gas drainage is insignificant in general.

The statistics of the gas extraction during the mining of the II1036 working face are illustrated as Fig. 10b. Similar to that of the II1034 working face, the gas extraction through II834 bed plate tunnel has the largest amount and the most stable flow rate $\left(38.2 \mathrm{~m}^{3} / \mathrm{min}\right.$ on maximum, $8.50 \mathrm{~m}^{3} / \mathrm{min}$ on average). However, the surface wells extraction is quite different from that in the II1034 working face. During the entire recovery process of the II1036 working face, the drainage curve of the surface wells is stable and the extraction amount $\left(18.02 \mathrm{~m}^{3} / \mathrm{min}\right.$ on maximum, $8.50 \mathrm{~m}^{3} / \mathrm{min}$ on average) can reach $50 \%-65 \%$ through the 11834 bed plate tunnel, this phenomenon may be attributed to the increased number of wells and that all of the wells are able to work properly. Moreover, the gas extraction through interception boreholes however is still small and can almost be negligible in whole.

[FIGURE 10]

What should be noted is, based on the gas parameters of No. 10 coal seam and the gas emission rate prediction by the method of different gas source (AQ 1018-2006), the gas emission quantities of II1034 and II1036 working face during their mining are $1.97 \mathrm{~m}^{3} / \mathrm{t}$ and 
$2.34 \mathrm{~m}^{3} / \mathrm{t}$ respectively. But the actual gas emission rate (including ventilation, high level boreholes and goaf burying pipes) of the two working faces ( 23.45 and $7.23 \mathrm{~m}^{3} / \mathrm{t}$ respectively) are far greater than the forecasted one, indicating that although comprehensive gas extraction measures have been taken into practice, there are still considerable amount of pressure-relief gas flowing into the mining working face through interlayer cracks. Thus, existing gas comprehensive control measures still need to be improved.

The statistics of gas drainage indicate that the total gas extraction amount during the recovery of II1034 and II1036 working faces reach $25131886.8 \mathrm{~m}^{3}\left(12771742.03 \mathrm{~m}^{3}\right.$ during the recovery of II1034 working face and $12360144.79 \mathrm{~m}^{3}$ during the recovery of II1036 working face), and the percentage of different methods for gas extraction is illustrated in Fig. 11. Deducting the gas emission from the No. 10 coal seam working faces themselves, the accumulated pressure-relief gas extraction quantities from the No. 8 coal seam is $23903532.66 \mathrm{~m}^{3}$, and the gas drainage rate of the protected seam reaches $78.58 \%$.

[FIGURE 11]

\subsubsection{Residual gas pressure and content}

According to the measurement results of residual gas pressure and gas content, the maximum residual gas pressure of No. 8 coal seam is $0.26 \mathrm{MPa}$, while the maximum residual gas content is $4.29 \mathrm{~m}^{3} / \mathrm{t}$. Both of the two parameters are less than the critical value $(0.74 \mathrm{MPa}$ and $8.0 \mathrm{~m}^{3} / \mathrm{t}$ respectively) of outburst risk which was formulated by the authority's provisions for the prevention of coal and gas outburst (SAWS, 2009). Moreover, all of the pressure/content measuring points, no matter inside or beside the theoretical unloading boundary, are all less than the above mentioned critical value, indicating that a protected range extension phenomenon (Wang et al., 2013a) has appeared and the unloading protection zone generated by the protective layer mining should be greater than that of the theoretical predicted one.

\section{Control effects verification of the remote lower protective seam mining}

\subsection{Gas emission during coal roadway driving}

After five years of gas control practice, the coal roadway driving of the 11832 working face began in April 11 1 th, 2014 and finished in October, 2014. The gas emission condition 
during the coal roadway driving of 11832 working face is shown in Fig. 12 . With the advancing of coal roadways, the gas emission from the wind roadway and belt conveyor roadway all exhibit the same tendency of increasing gas emission and this phenomenon is relevant to the fact that the tunneling place is gradually approaching the not protected area of II832 working face. Although a dense borehole gas extraction method was adopted in the not protected area to eliminate the outburst risk, with a much weaker unloading effect the gas extraction result is poorer than the coals located inside the theoretical unloading boundary and the gas content will also be higher than that in the protected area. Consequently, when the tunneling place gets close to or enters this area, the gas emission amount will then inevitably increase.

The maximum gas emission in wind roadway is $2.14 \mathrm{~m}^{3} / \mathrm{min}$ with a maximum gas concentration in return air of $0.51 \%$, and the maximum gas emission in belt conveyor roadway reaches $1.43 \mathrm{~m}^{3} / \mathrm{min}$ with a maximum return air gas concentration of $0.34 \%$. The gas emission rate in the belt conveyor roadway side is significantly lower than that of wind roadway side, indicating the unloading magnitude of the coal mass in belt conveyor roadway side is much better and which is consistent with the numerical simulation results.

Additionally, a rapid increase of the emission rate can be found about $50 \mathrm{~m}$ outside the theoretical unloading boundary in Fig. 12a, demonstrating that a protected range extension phenomenon of the protective seam mining may exist.

[FIGURE 12]

\subsection{Gas emission quantity during recovery}

The recovery of the 11832 working face began on December $7^{\text {th }}, 2014$ and finished in October, 2015. The gas emission situation during the recovery of 11832 working face is shown in Fig. 13.

At the initial stage of the working face recovery, the gas emission quantity gradually increases from $1.34 \mathrm{~m}^{3} / \mathrm{min}$ to a maximum value of $20.47 \mathrm{~m}^{3} / \mathrm{min}$ (recovery distance is $42 \mathrm{~m}$ ), and then with the working face advancing, the gas emission tends to be stable at about $17 \mathrm{~m}^{3} / \mathrm{min}$. When the recovery distance exceeds $90 \mathrm{~m}$, the emission rate shows a rapid decay to about $8.5 \mathrm{~m}^{3} / \mathrm{min}$, indicating that the gas content in this area receives an obvious decrease. After that, the gas emission rate stabilizes at $6.5-8.0 \mathrm{~m}^{3} / \mathrm{min}$. 
The gas concentration in the return air during the recovery of the 11832 working face shows similar tendency of the gas emission, with an initial gas concentration of $0.05 \%$ and then rapidly increase to a maximum of $0.77 \%$. When the recovery distance exceeds $100 \mathrm{~m}$ the concentration quickly decrease to about $0.25-0.4 \%$ and finally stabilizes at $0.15 \%$.

The obvious decrease of the gas emission rate and gas concentration in return air during the recovery of 11832 working face, which can be found about $50 \mathrm{~m}$ outside the theoretical unloading boundary (Fig. 13), is consistent with the gas emission rate variation tendency during coal roadway driving (Fig. 12a), indicating that a protected range extension phenomenon of protective seam mining is definitely existing and requires a further study.

[FIGURE 13]

\section{Conclusions}

1) The numerical simulation research and the engineering practice study of the protective seam mining in II3 District, Zhuxianzhuang Coal Mine demonstrate that remote lower protective seam mining (average layer spacing: $78 \mathrm{~m}$ ) can effectively lead to a unloading of the overlying coal/rock mass and a permeability increase in the protected seam. After the mining of the protective seam (II1034 and II1036 working face), the permeability of the protected seam (II832 working face) increased by 4320 times with a maximum expansion deformation rate of $33.4 \%$. Combining with the pressure-relief gas extraction, the gas drainage rate of the protected seam reaches $78.58 \%$ and the maximum residual gas pressure / content of the protected seam remain $0.26 \mathrm{MPa}$ and $4.29 \mathrm{~m}^{3} / \mathrm{t}$ respectively, which indicate that the coal and gas outburst risk of the 11832 working face was completely eliminated.

2) Among the pressure-relief gas drainage measures, the method of the penetrating boreholes extraction in bed plate tunnel works the best. During the entire extraction process the drainage amount from the bed plate tunnel is the largest (accounting for $42.58-55.09 \%$ of the total pressure-relief gas) and the flow rate stays stable $\left(8.50-9.95 \mathrm{~m}^{3} / \mathrm{min}\right.$ on average). The effects of the surface wells extraction is closely related to the number of wells and whether the well can work properly or not. In this case, with five properly worked surface wells (spacing is $120 \mathrm{~m}$ ), the extraction amount of the surface wells contributes $30.88 \%$ of the total pressure-relief gas which is considerable in eliminating the outburst risk of the No. 8 
coal seam. However, unlike the above-mentioned measures, gas extraction through the interception boreholes is almost negligible in whole. Additionally, it should be noted that although comprehensive gas extraction measures have been taken into practice, there are still considerable amount of pressure-relief gas flowing into the protective seam working face through inter layer cracks, which calls for improvements on the existing gas control measures.

3) Residual gas pressure/content measuring show that all of the results, no matter inside or beside the theoretical unloading boundary, are less than the critical value (0.74MPa and $8.0 \mathrm{~m}^{3} / \mathrm{t}$, respectively). And the gas emission during coal roadway driving or working face recovery also demonstrate that an obvious increase of the gas content can be found about $50 \mathrm{~m}$ outside the theoretical unloading boundary. All of the facts listed above indicate that a protected range extension phenomenon of the protective seam mining is existing and the protected area generated by the protective seam mining should be larger than that of the theoretical predicted one, and thus a further study is needed.

\section{Acknowledgements}

The authors are grateful to the financial support from the Project Funded by the Priority Academic Program Development of Jiangsu Higher Education Institutions (PAPD), the National Science Foundation of China (No. 51374204, No. 51574229 and No. 51404260), the Basic Research Program of Jiangsu Province (No. BK20140206).), the Fundamental Research Funds for the Central Universities (No. 2015XKMS006, No. 2015XKMS004). 


\section{References}

Aguado, M.B.D., Nicieza, C.G., 2007. Control and prevention of gas outbursts in coal mines, Riosa-Olloniego coalfield, Spain. International Journal of Coal Geology 69, 253-266.

Bao, Y., Wei, C., Neupane, B., 2016. Generation and accumulation characteristics of mixed coalbed methane controlled by tectonic evolution in Liulin CBM field, eastern Ordos Basin, China. Journal of Natural Gas Science and Engineering 28, 262-270.

Beamish, B.B., Crosdale, P.J., 1998. Instantaneous outbursts in underground coal mines: an overview and association with coal type. International Journal of Coal Geology 35, 27-55.

Brauner, G., 1994. Rockbursts in coal mines and their prevention. CRC Press.

Bustin, R., Clarkson, C., 1998. Geological controls on coalbed methane reservoir capacity and gas content. International Journal of Coal Geology 38, 3-26.

Chen, H.-D., Cheng, Y.-P., Zhou, H.-X., Li, W., 2013. Damage and permeability development in coal during unloading. Rock mechanics and rock engineering 46, 1377-1390.

Cheng, Y., Wang, H., Wang, L., Zhou, H., Liu, H., Liu, H., Wu, D., Li, W., 2010. Theories and engineering applications on coal mine gas control. China University of Mining and Technology Press, Xuzhou.

Cheng, Y., Wang, L., Liu, H., Kong, S., Yang, Q., Zhu, J., Tu, Q., 2015. Definition, theory, methods, and applications of the safe and efficient simultaneous extraction of coal and gas. International Journal of Coal Science \& Technology 2, 52-65.

Cheng, Y., Yu, Q., 2007. Development of regional gas control technology for Chinese coalmines. Journal of Mining \& Safety Engineering 24, 383-390.

Cheng, Y., Yu, Q., Yuan, L., 2004. Experimental research of safe and high-efficient exploitation of coal and pressure relief gas in long distance. Journal-China University of Mining And Technology-Chinese Edition $33,132-136$.

Creedy, D., Tilley, H., 2003. Coalbed methane extraction and utilization. Proceedings of the Institution of Mechanical Engineers, Part A: Journal of Power and Energy 217, 19-25.

Diamond, W.P., Schatzel, S.J., 1998. Measuring the gas content of coal: a review. International Journal of Coal Geology 35, 311-331.

Flores, R.M., 1998. Coalbed methane: From hazard to resource. International Journal of Coal Geology 35, 3-26.

Guo, P., Cheng, Y., Jin, K., Liu, Y., 2014. The impact of faults on the occurrence of coal bed methane in Renlou coal mine, Huaibei coalfield, China. Journal of Natural Gas Science and Engineering 17, 151-158.

Guo, W., Xu, F., 2016. Numerical simulation of overburden and surface movements for Wongawilli strip pillar mining. International Journal of Mining Science and Technology 26, 71-76.

Jiang, J.-Y., Cheng, Y.-P., Wang, L., Li, W., Wang, L., 2011. Petrographic and geochemical effects of sill intrusions on coal and their implications for gas outbursts in the Wolonghu Mine, Huaibei Coalfield, China. International Journal of Coal Geology 88, 55-66.

Jiang, J., Cheng, Y., Mou, J., Jin, K., Cui, J., 2015a. Effect of Water Invasion on Outburst Predictive Index of Low Rank Coals in Dalong Mine. PloS one 10, e0132355.

Jiang, J., Cheng, Y., Zhang, P., Jin, K., Cui, J., Du, H., 2015b. CBM drainage engineering challenges and the technology of mining protective coal seam in the Dalong Mine, Tiefa Basin, China. Journal of Natural Gas Science and Engineering 24, 412-424.

Jin, K., Cheng, Y., Wang, L., Dong, J., Guo, P., An, F., Jiang, L., 2015. The effect of sedimentary redbeds on coalbed methane occurrence in the Xutuan and Zhaoji Coal Mines, Huaibei Coalfield, China. International Journal of Coal Geology 137, 111-123.

Karacan, C.Ö., Ruiz, F.A., Cotè, M., Phipps, S., 2011. Coal mine methane: a review of capture and utilization 
practices with benefits to mining safety and to greenhouse gas reduction. International Journal of Coal Geology 86, 121-156.

Kissell, F.N., 2006. Handbook for Methane Control in Mining. NIOSH.

Kong, S., Cheng, Y., Ren, T., Liu, H., 2014. A sequential approach to control gas for the extraction of multi-gassy coal seams from traditional gas well drainage to mining-induced stress relief. Applied Energy 131, 67-78.

Krause, E., Skiba, J., 2014. Formation of methane hazard in longwall coal mines with increasingly higher production capacity. International Journal of Mining Science and Technology 24, 403-407.

Lama, R., Saghafi, A., 2002. Overview of gas outbursts and unusual emissions, in: Aziz, N. (Ed.), Coal 2002: Coal Operators' Conference, University of Wollongong \& the Australasian Institute of Mining and Metallurgy, pp. 74-88.

Li, D., 2014. Underground hydraulic mining of thin sub-layer as protective coal seam in coal mines. International Journal of Rock Mechanics and Mining Sciences 67, 145-154.

Li, H., Lin, B., Yang, W., Gao, Y., Liu, T., 2015. Effects of an underlying drainage gallery on coal bed methane capture effectiveness and the mechanical behavior of a gate road. Journal of Natural Gas Science and Engineering 27, 616-631.

Li, W., Cheng, Y.-P., Wang, L., 2011. The origin and formation of CO 2 gas pools in the coal seam of the Yaojie coalfield in China. International Journal of Coal Geology 85, 227-236.

Li, W., Cheng, Y.P., Guo, P.K., An, F.H., Chen, M.Y., 2014. The evolution of permeability and gas composition during remote protective longwall mining and stress-relief gas drainage: a case study of the underground Haishiwan Coal Mine. Geosciences Journal 18, 427-437.

Liu, H., Cheng, Y., 2015. The elimination of coal and gas outburst disasters by long distance lower protective seam mining combined with stress-relief gas extraction in the Huaibei coal mine area. Journal of Natural Gas Science and Engineering 27, 346-353.

Liu, H., Cheng, Y., Chen, H., Mou, J., Kong, S., 2013. Characteristics of mining gas channel expansion in the remote overlying strata and its control of gas flow. International Journal of Mining Science and Technology $23,481-487$.

Liu, H., Cheng, Y., Song, J., Shang, Z., Wang, L., 2009a. Pressure relief, gas drainage and deformation effects on an overlying coal seam induced by drilling an extra-thin protective coal seam. Mining Science and Technology (China) 19, 724-729.

Liu, H., Cheng, Y., Zhou, H., Wang, F., Chen, H., 2010. Fissure evolution and evaluation of pressure-relief gas drainage in the exploitation of super-remote protected seams. Mining Science and Technology (China) 20, $178-182$.

Liu, H., Liu, H., Cheng, Y., 2014. The elimination of coal and gas outburst disasters by ultrathin protective seam drilling combined with stress-relief gas drainage in Xinggong coalfield. Journal of Natural Gas Science and Engineering 21, 837-844.

Liu, L., Cheng, Y., Wang, H., Wang, L., 2009b. Principle and engineering application of pressure relief gas drainage in low permeability outburst coal seam. Mining Science and Technology (China) 19, 342-345.

Liu, Y.-K., Zhou, F.-B., Liu, L., Liu, C., Hu, S.-Y., 2011. An experimental and numerical investigation on the deformation of overlying coal seams above double-seam extraction for controlling coal mine methane emissions. International Journal of Coal Geology 87, 139-149.

Lu, S.-q., Cheng, Y.-p., Li, W., Wang, L., 2015a. Pore structure and its impact on CH4 adsorption capability and diffusion characteristics of normal and deformed coals from Qinshui Basin. International Journal of Oil, Gas and Coal Technology 10, 94-114.

Lu, S., Cheng, Y., Li, W., 2016. Model development and analysis of the evolution of coal permeability under different boundary conditions. Journal of Natural Gas Science and Engineering 31, 129-138. 
Lu, S., Cheng, Y., Ma, J., Zhang, Y., 2014. Application of in-seam directional drilling technology for gas drainage with benefits to gas outburst control and greenhouse gas reductions in Daning coal mine, China. Natural Hazards 73, 1419-1437.

Lu, S., Cheng, Y., Qin, L., Li, W., Zhou, H., Guo, H., 2015b. Gas desorption characteristics of the high-rank intact coal and fractured coal. International Journal of Mining Science and Technology 25, 819-825.

Noack, K., 1998. Control of gas emissions in underground coal mines. International Journal of Coal Geology 35 , 57-82.

State Administration of Work Safety, 2008. Technical criterion of protective coal seam exploitation. China Coal Industry Publishing House, Beijing.

State Administration of Work Safety, 2009. Provisions of the Prevention of Coal and Gas Outburst. China Coal Industry Publishing House, Beijing.

Shepherd, J., Rixon, L., Griffiths, L., 1981. Outbursts and geological structures in coal mines: a review, International Journal of Rock Mechanics and Mining Sciences \& Geomechanics Abstracts. Elsevier, pp. 267-283.

Song, C.-s., Li, D.-h., Li, H.-m., 2009. Modeling and simulation of strata movement for protective seam mining with large interburden. Journal of Coal Science and Engineering (China) 15, 46-49.

Su, X., Lin, X., Zhao, M., Song, Y., Liu, S., 2005. The upper Paleozoic coalbed methane system in the Qinshui basin, China. AAPG bulletin 89, 81-100.

Tao, M., Shi, B., Li, J., Wang, W., Li, X., Gao, B., 2007. Secondary biological coalbed gas in the Xinji area, Anhui province, China: Evidence from the geochemical features and secondary changes. International journal of coal geology 71, 358-370.

Thakur, P.C., 2006. Coal seam degasification, in: Kissell, F.N. (Ed.), Handbook for Methane Control in Mining. NIOSH.

Tu, M., Huang, N., Liu, B., 2007. Research on pressure relief effect of overlying coal rock body using far distance lower protective seam exploitation method. Journal of Mining \& Safety Engineering 24, 418-421.

Wang, H., Cheng, Y., Liu, G., Kong, S., Zhang, R., 2013a. Range extender of protection and continuous mining technology of protected seam. Journal of Mining \& Safety Engineering 30, 595-599.

Wang, H., Cheng, Y., Wang, W., Xu, R., 2014. Research on comprehensive CBM extraction technology and its applications in China's coal mines. Journal of Natural Gas Science and Engineering 20, 200-207.

Wang, H., Cheng, Y., Yuan, L., 2013b. Gas outburst disasters and the mining technology of key protective seam in coal seam group in the Huainan coalfield. Natural Hazards 67, 763-782.

Wang, L., Cheng, Y., Li, F., Wang, H., Liu, H., 2008. Fracture evolution and pressure relief gas drainage from distant protected coal seams under an extremely thick key stratum. Journal of China University of Mining and Technology 18, 182-186.

Wang, L., Cheng, Y., Wang, L., Guo, P., Li, W., 2012. Safety line method for the prediction of deep coal-seam gas pressure and its application in coal mines. Safety science 50, 523-529.

Wang, L., Wang, Z., Xu, S., Zhou, W., Wu, J., 2015a. A field investigation of the deformation of protected coal and its application for CBM extraction in the Qinglong coalmine in China. Journal of Natural Gas Science and Engineering 27, 367-373.

Wang, S., Elsworth, D., Liu, J., 2013c. Permeability evolution during progressive deformation of intact coal and implications for instability in underground coal seams. International Journal of Rock Mechanics and Mining Sciences 58, 34-45.

Wang, W., Haifeng, W., Xu, Z., Rong, Z., 2015b. Influence of section coal pillar width of the protective layer on pressure-relief effect of the protected layer. 20, 5453-5464.

Wu, X., Dou, L., Lv, C., Cao, A., MingWei, Z., 2011. Research on pressure-relief effort of mining 
upper-protective seam on protected seam. Procedia Engineering 26, 1089-1096.

Yang, K., He, X., Dou, L., Liu, W., Sun, L., Ye, H., 2015. Experimental investigation into stress-relief characteristics with upward large height and upward mining under hard thick roof. International Journal of Coal Science \& Technology 2, 91-96.

Yang, T., Xu, T., Liu, H., Tang, C., Shi, B., Yu, Q., 2011a. Stress-damage-flow coupling model and its application to pressure relief coal bed methane in deep coal seam. International Journal of Coal Geology 86, 357-366.

Yang, W., Lin, B.-q., Qu, Y.-a., Li, Z.-w., Zhai, C., Jia, L.-1., Zhao, W.-q., 2011b. Stress evolution with time and space during mining of a coal seam. International journal of rock mechanics and mining sciences 48 , $1145-1152$.

Yang, W., Lin, B.-q., Qu, Y.-a., Zhao, S., Zhai, C., Jia, L.-1., Zhao, W.-q., 2011c. Mechanism of strata deformation under protective seam and its application for relieved methane control. International Journal of Coal Geology 85, 300-306.

Yu, Q., Cheng, Y., 2012. Coal Mine Gas Control. China University of Mining and Technology Press, Xuzhou.

Yuan, L., 2003. Research on gas drainage technology for seam group with complicated and difficult conditions. Coal Science and Technology 31, 1-4.

Zhang, C., Tu, S., Bai, Q., Yang, G., Zhang, L., 2015a. Evaluating pressure-relief mining performances based on surface gas venthole extraction data in longwall coal mines. Journal of Natural Gas Science and Engineering 24, 431-440.

Zhang, N., Xue, F., Zhang, N., Feng, X., 2015b. Patterns and security technologies for co-extraction of coal and gas in deep mines without entry pillars. International Journal of Coal Science \& Technology 2, 66-75.

Zhao, W., Cheng, Y., Jiang, H., Jin, K., Wang, H., Wang, L., 2016. Role of the rapid gas desorption of coal powders in the development stage of outbursts. Journal of Natural Gas Science and Engineering 28, 491-501.

Zheng, L., Liu, G., Qi, C., Zhang, Y., Wong, M., 2008. The use of sequential extraction to determine the distribution and modes of occurrence of mercury in Permian Huaibei coal, Anhui Province, China. International Journal of Coal Geology 73, 139-155.

Zhou, H., Yang, Q., Cheng, Y., Ge, C., Chen, J., 2014. Methane drainage and utilization in coal mines with strong coal and gas outburst dangers: A case study in Luling mine, China. Journal of Natural Gas Science \& Engineering 20, 357-365.

Zhou, H., Zhang, R., Cheng, Y., Dai, H., Ge, C., Chen, J., 2015a. Methane and coal exploitation strategy of highly outburst-prone coal seam configurations. Journal of Natural Gas Science and Engineering 23, 63-69.

Zhou, S., Lin, B., 1997. The theory of gas flow and storage in coal seams. China Coal Industry Publishing House, Beijing.

Zhou, Y., Li, Z., Yang, Y., Wang, M., Gu, F., Ji, H., 2015b. Effect of adsorption-induced matrix deformation on coalbed methane transport analyzed using fractal theory. Journal of Natural Gas Science and Engineering 26, $840-846$ 


\section{Figures}

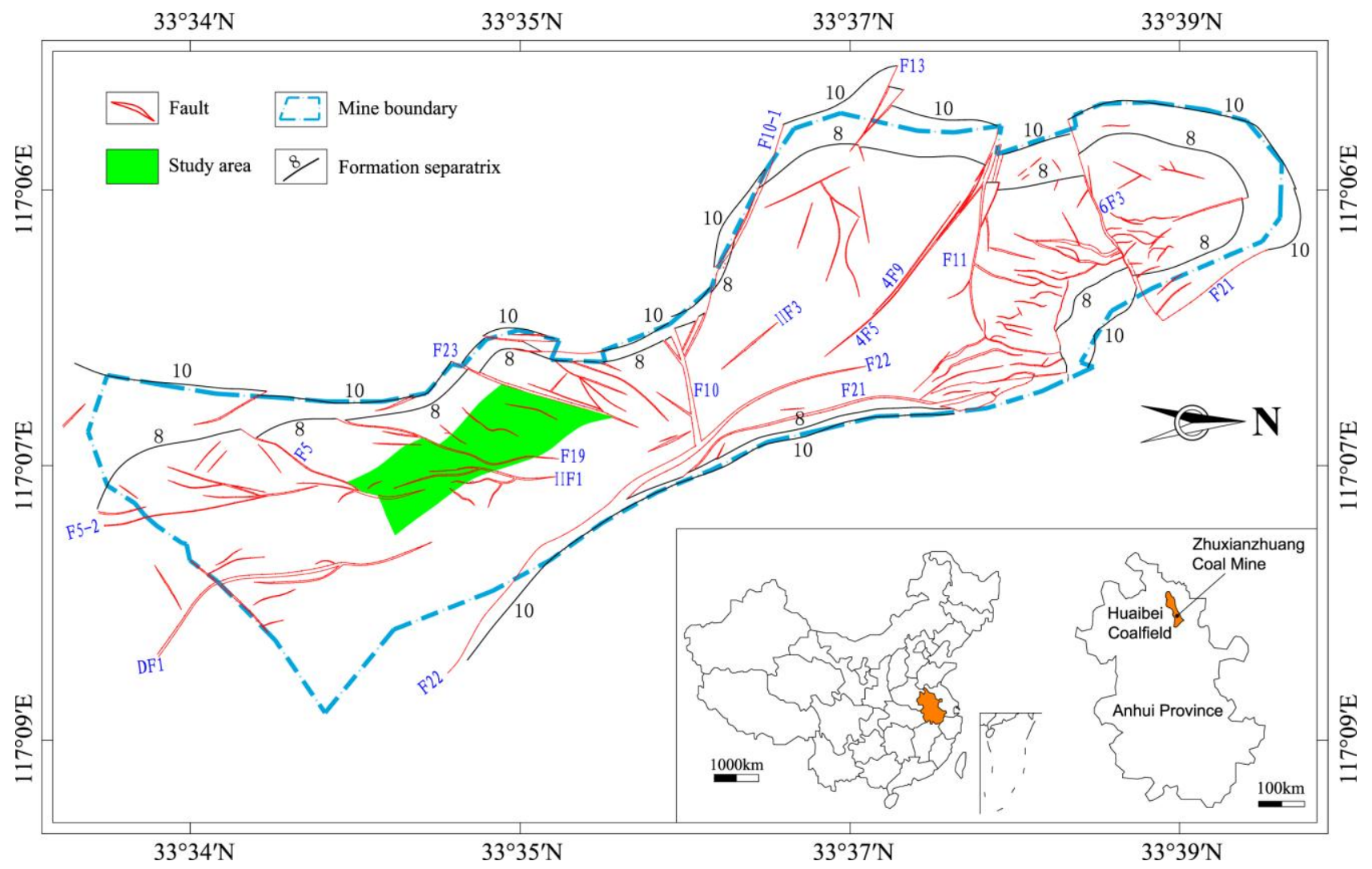

Fig. 1. Map showing the location of the study area and the geological structure outline of the Zhuxianzhuang Coal Mine.
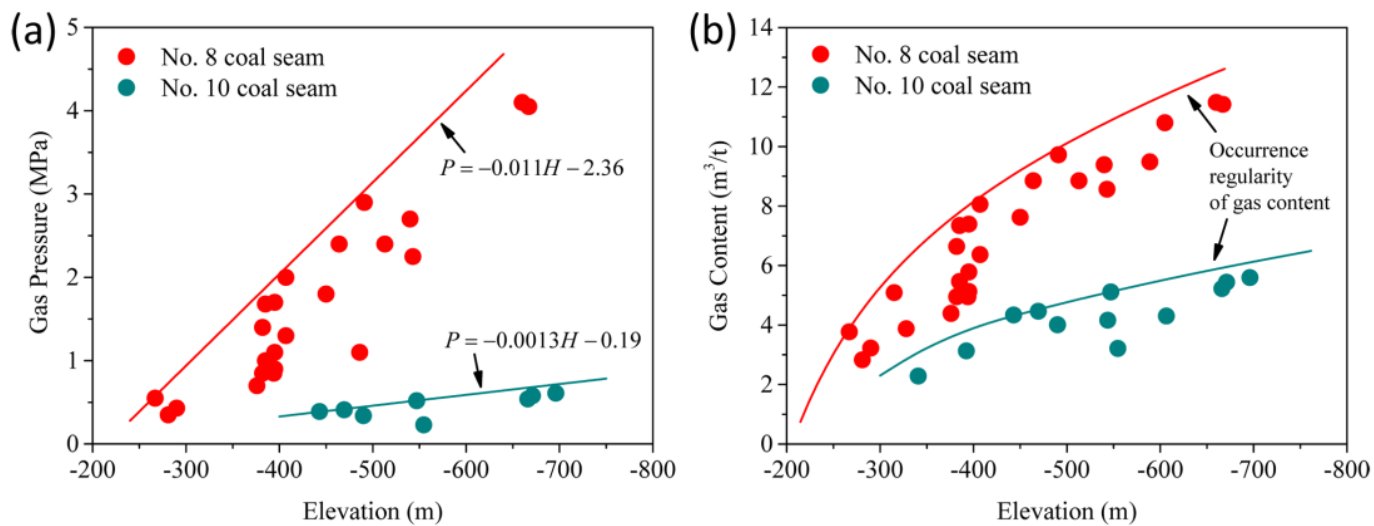

Fig. 2. Occurrence regularities of the gas pressure (a) and gas content (b) in the II3 District, Zhuxianzhuang Coal Mine. 


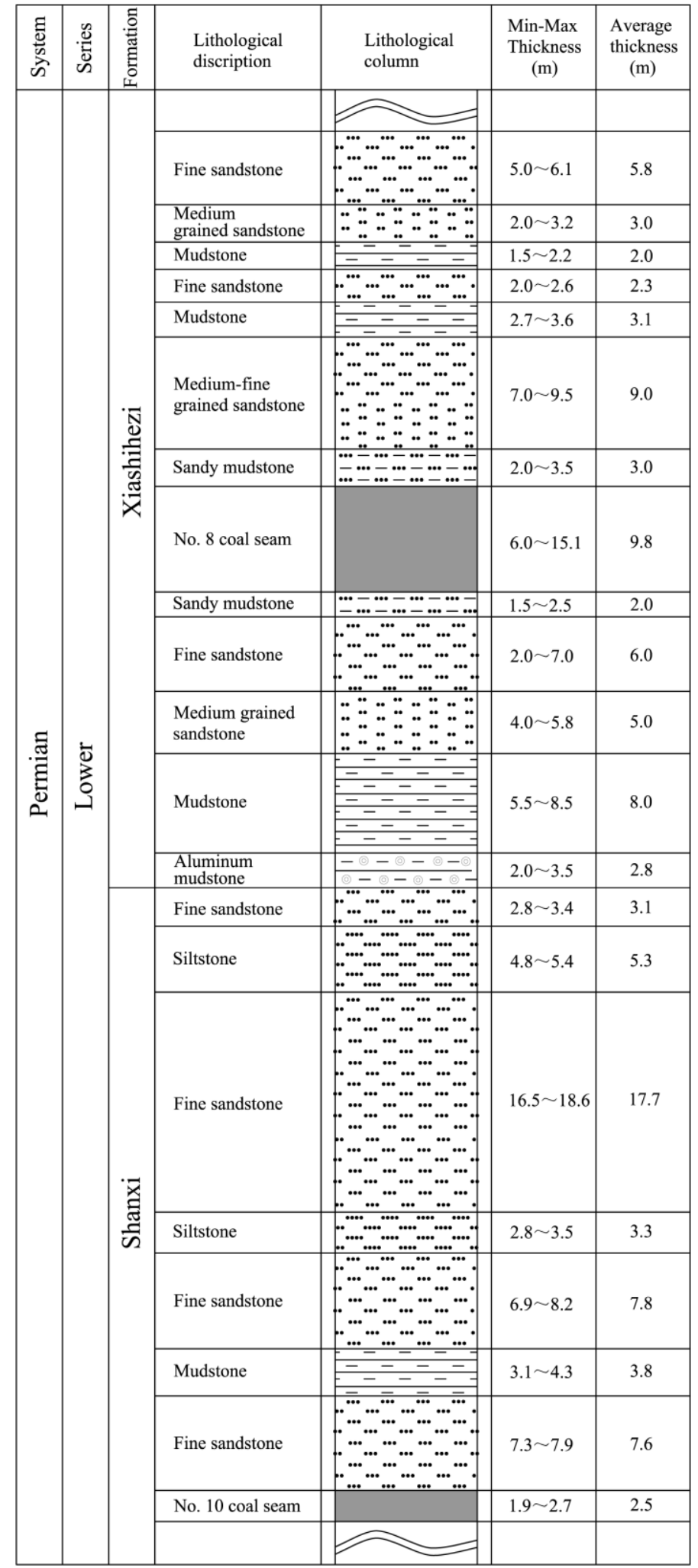

Fig. 3. Generalized stratigraphy of the II3 District, Zhuxianzhuang Coal Mine. 


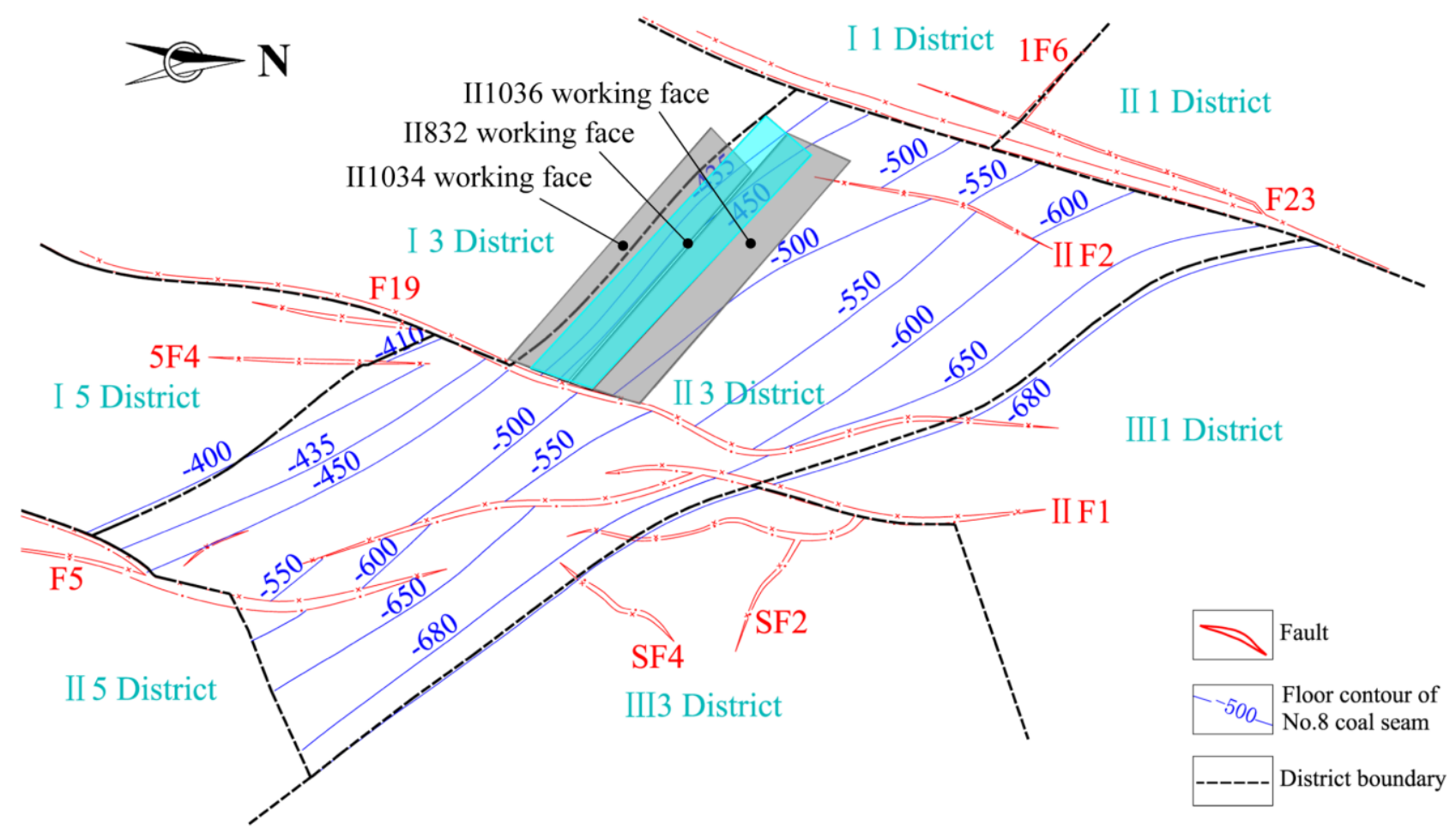

Fig. 4. Map showing the geological structure outline of the II3 District, Zhuxianzhuang Coal Mine.

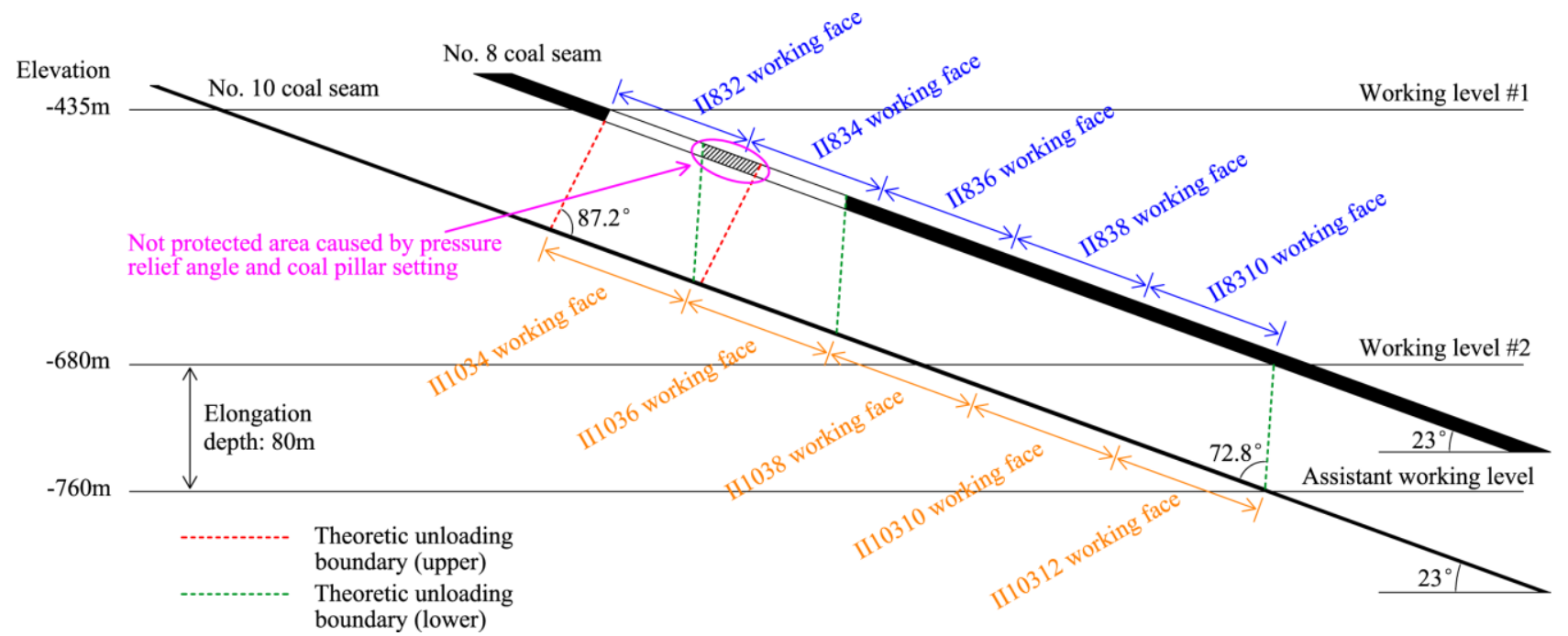

Fig. 5 Schematic diagram showing the design of the protective seam mining. 


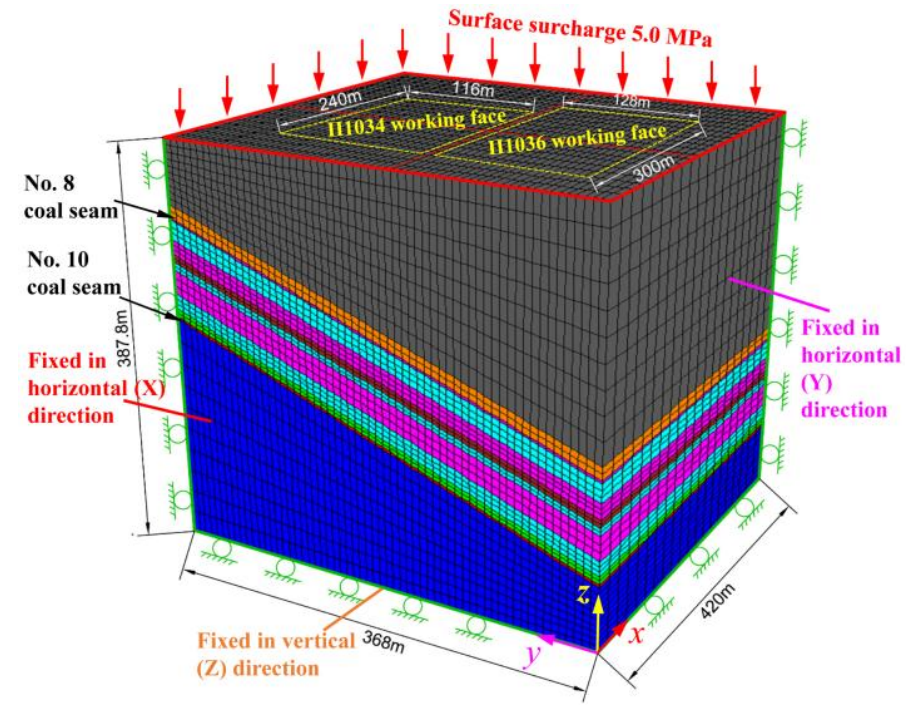

Fig. 6 Geometry and boundaries of the numerical simulation model.

(a)

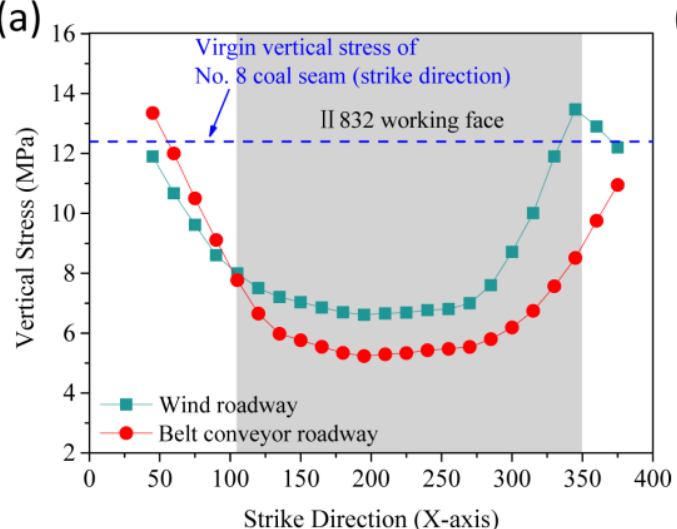

(c)

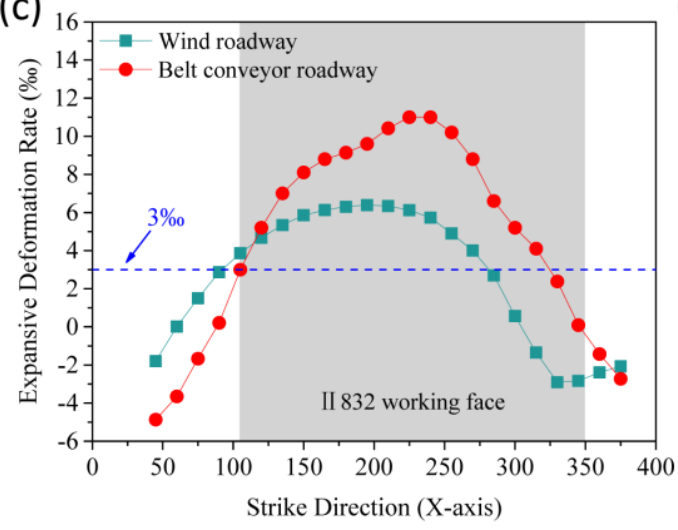

(b)

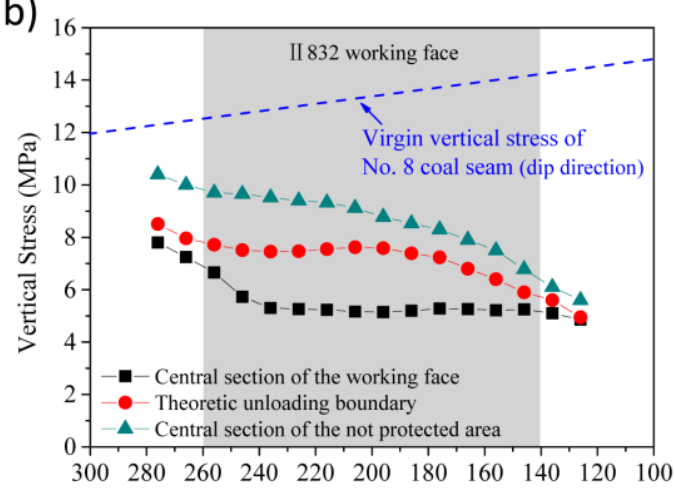

(d)

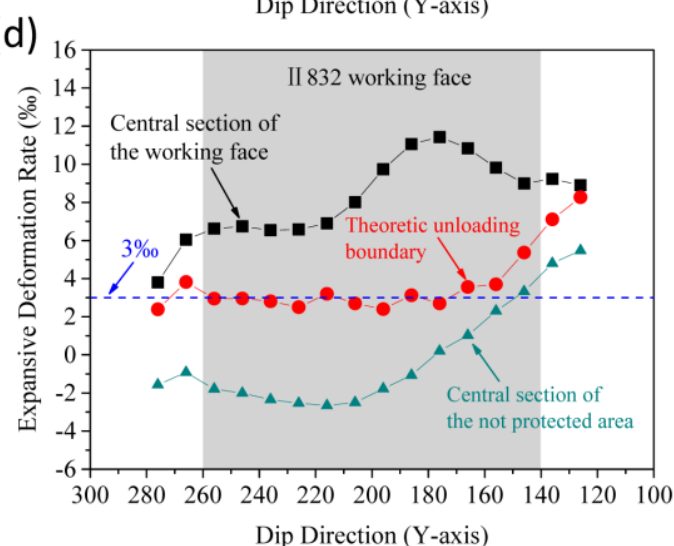

Fig. 7 Variations of the protected seam's vertical stress and expansion deformation after the mining of protective seam 


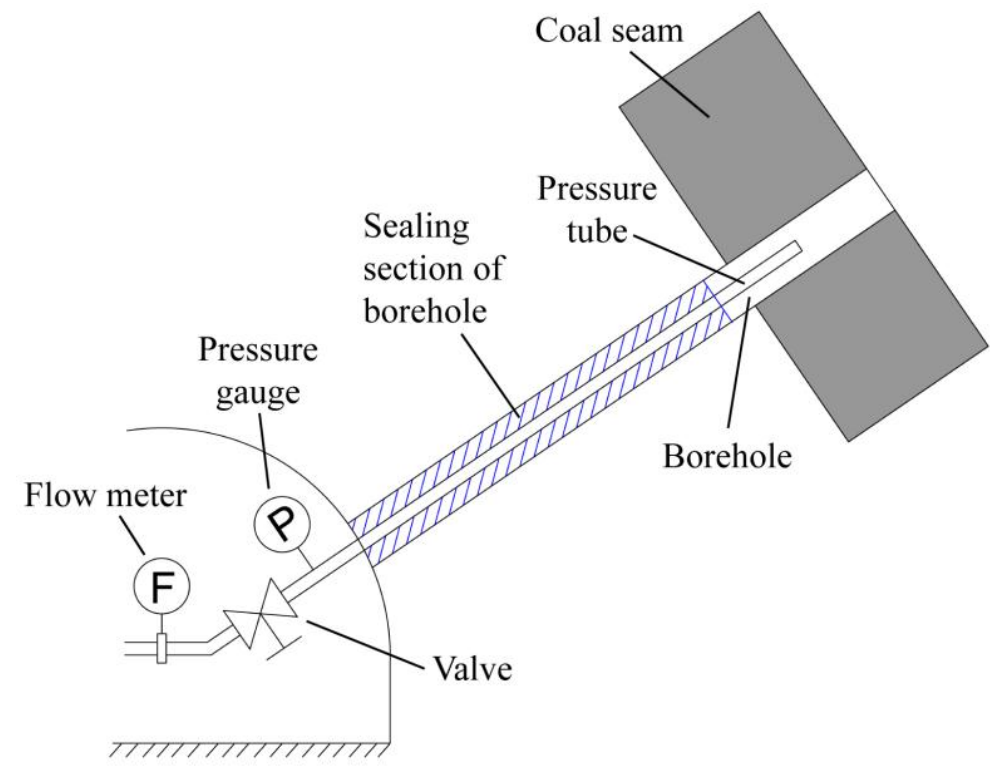

Fig. 8 Schematic diagram showing the measurement of coal seam permeability.
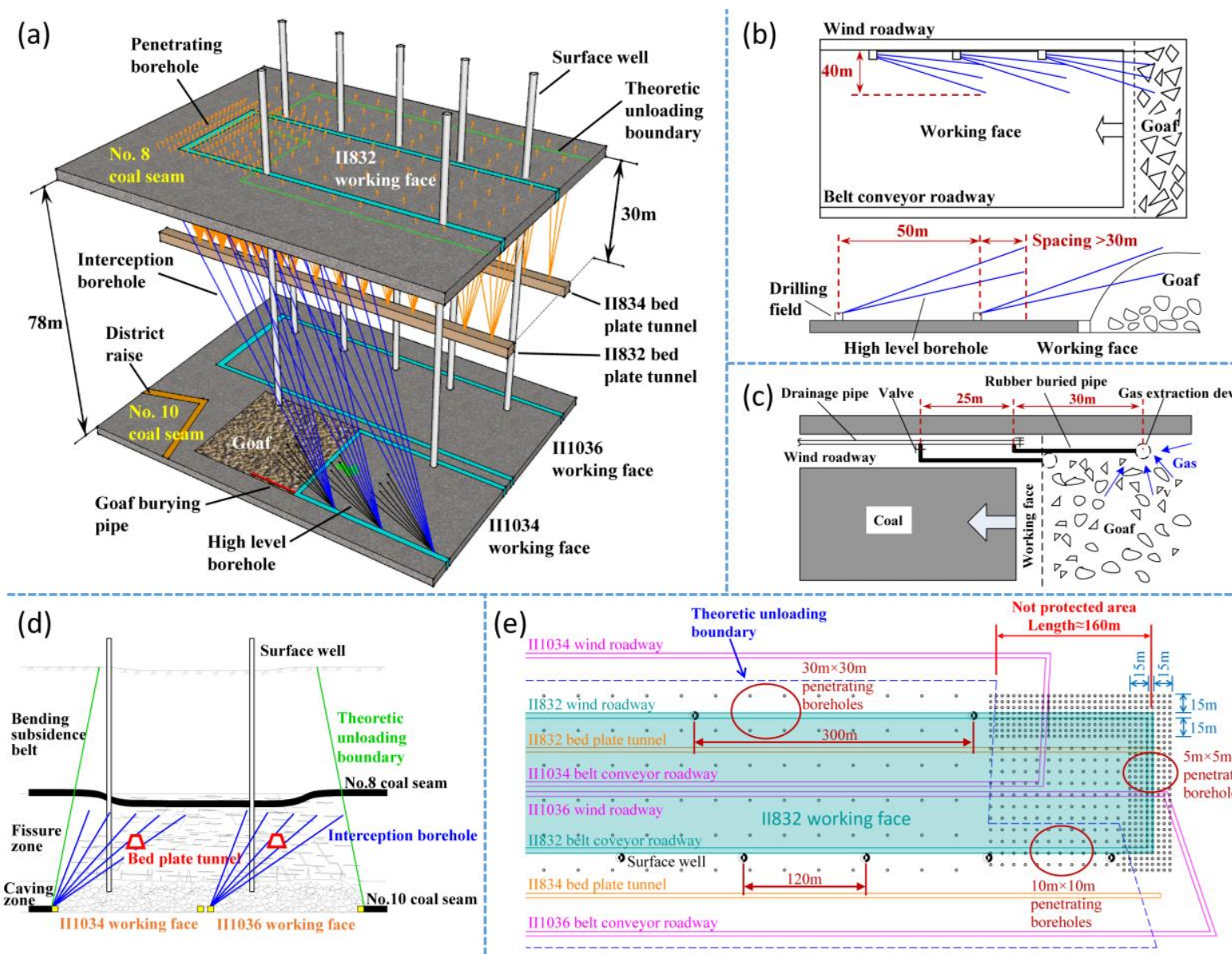

(C) Drainage pipe Valve ${ }_{25 \mathrm{~m}}^{\text {Rubber buried pipe }}$ Gas extraction device

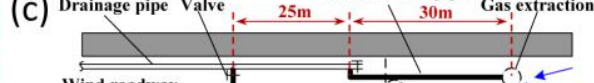

II1036

working face
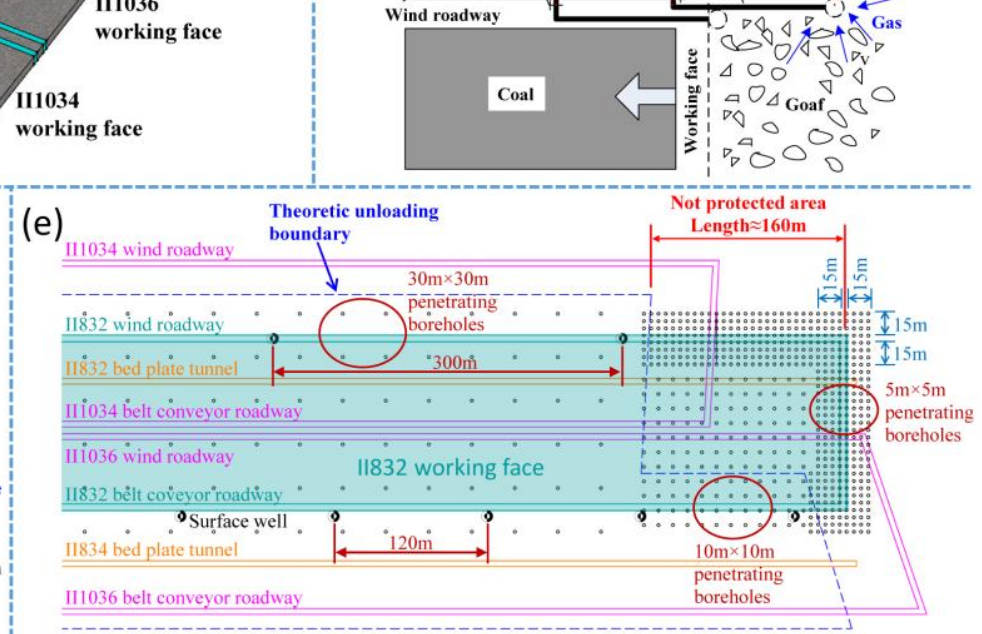

Fig. 9 Schematic diagram showing the gas extraction design during the protective seam mining. 

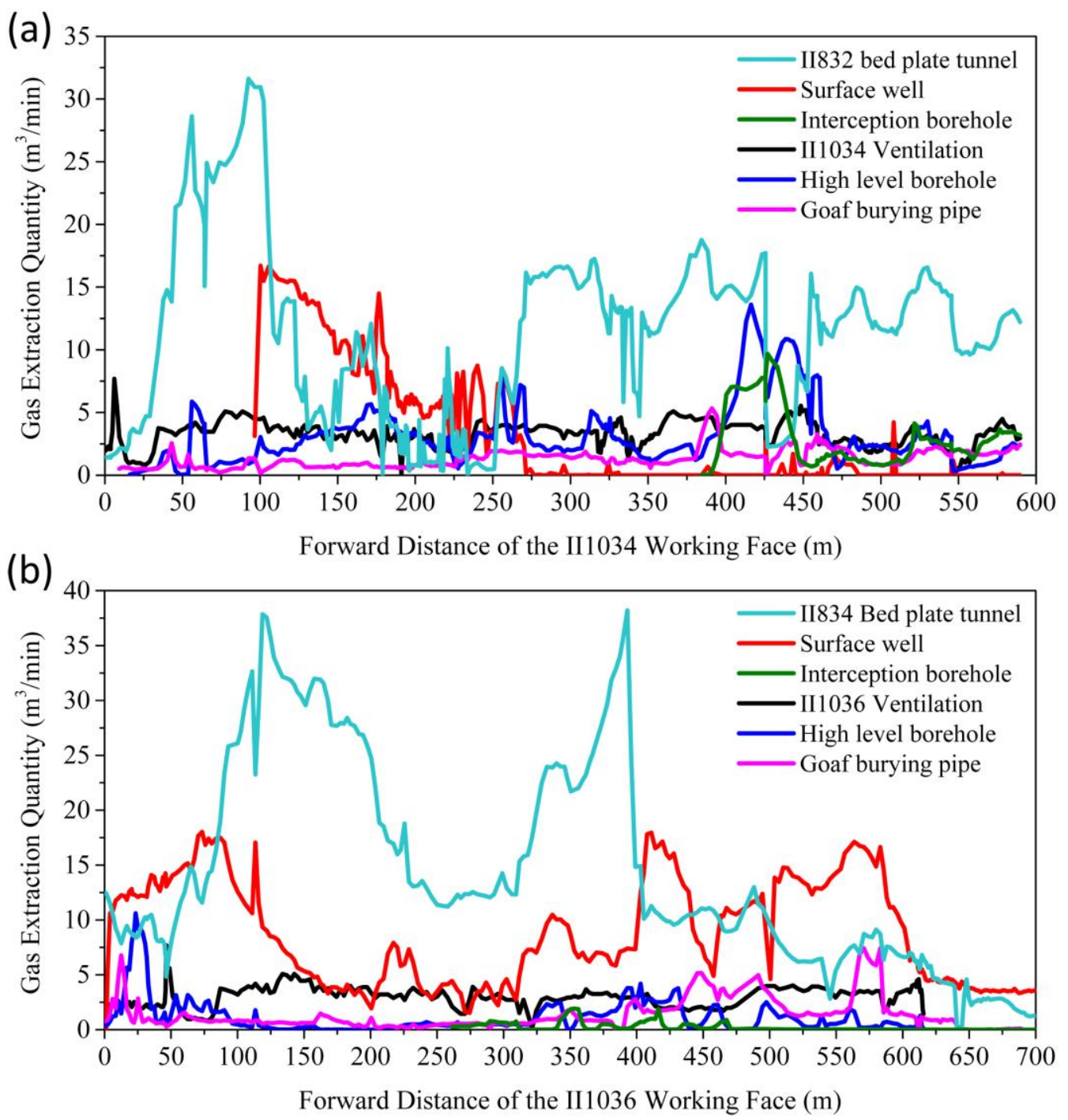

Fig. 10 Statistics of gas extraction amount during the protective seam mining.

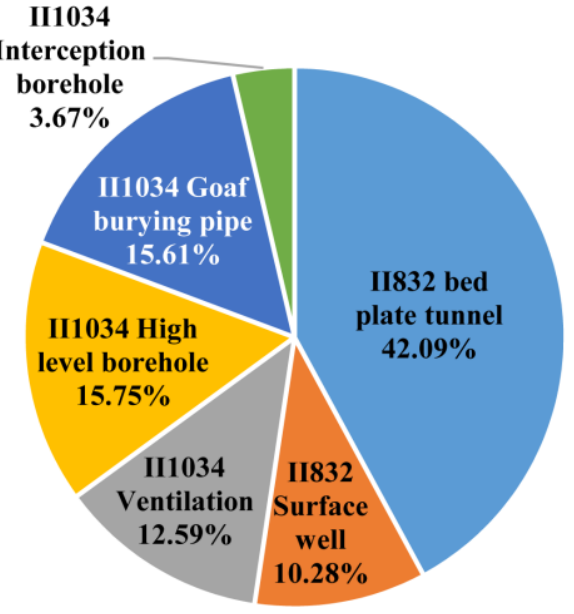

(a)

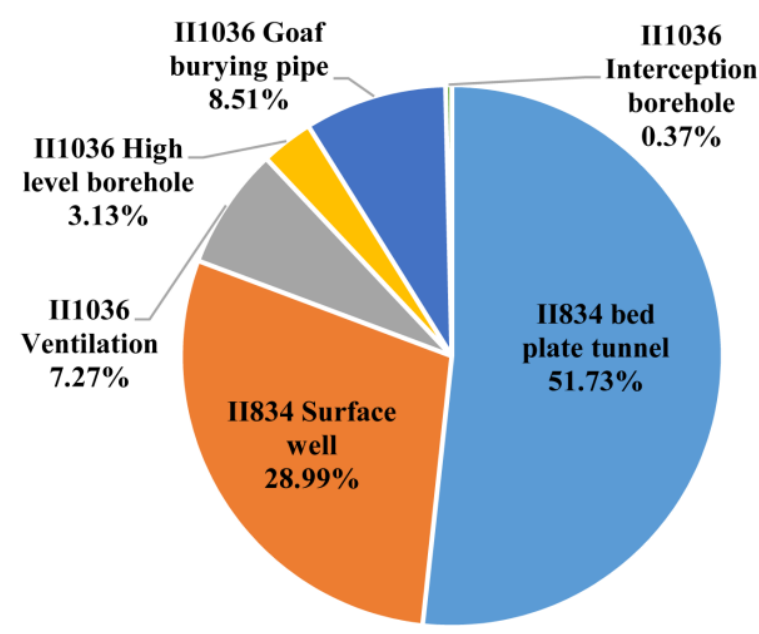

(b)

Fig. 11 Statistics of gas extraction during the mining of II1034 (a) and II1036 (b) working face. 

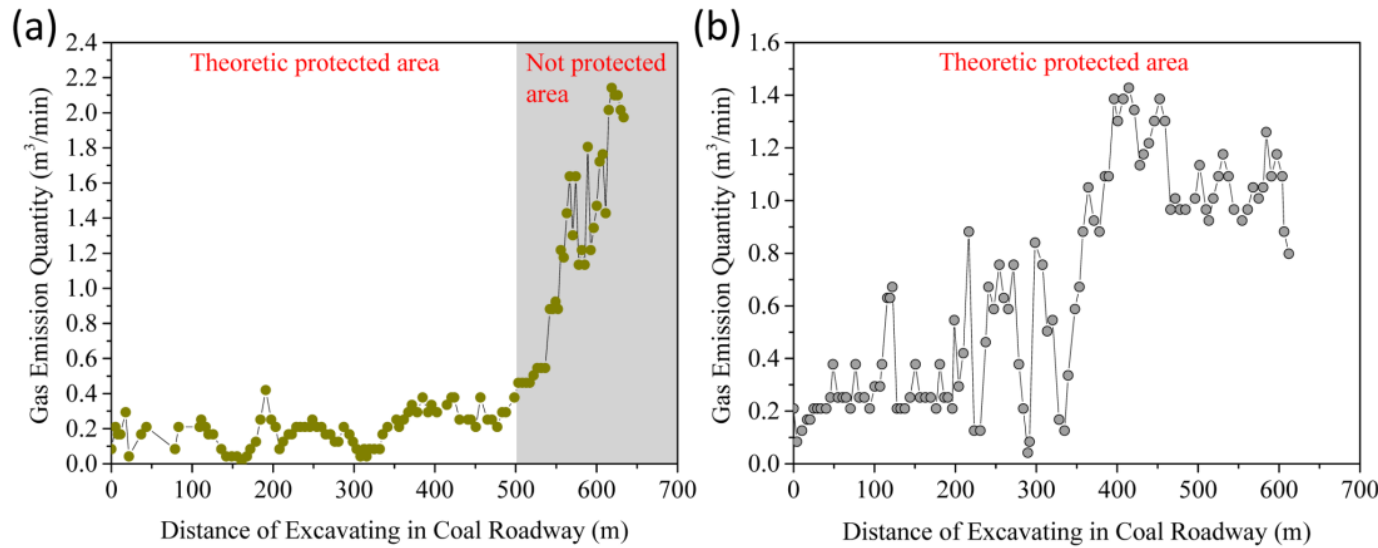

Fig. 12 Gas emission during the excavation of II832 working face's wind roadway (a) and belt conveyor roadway (b).
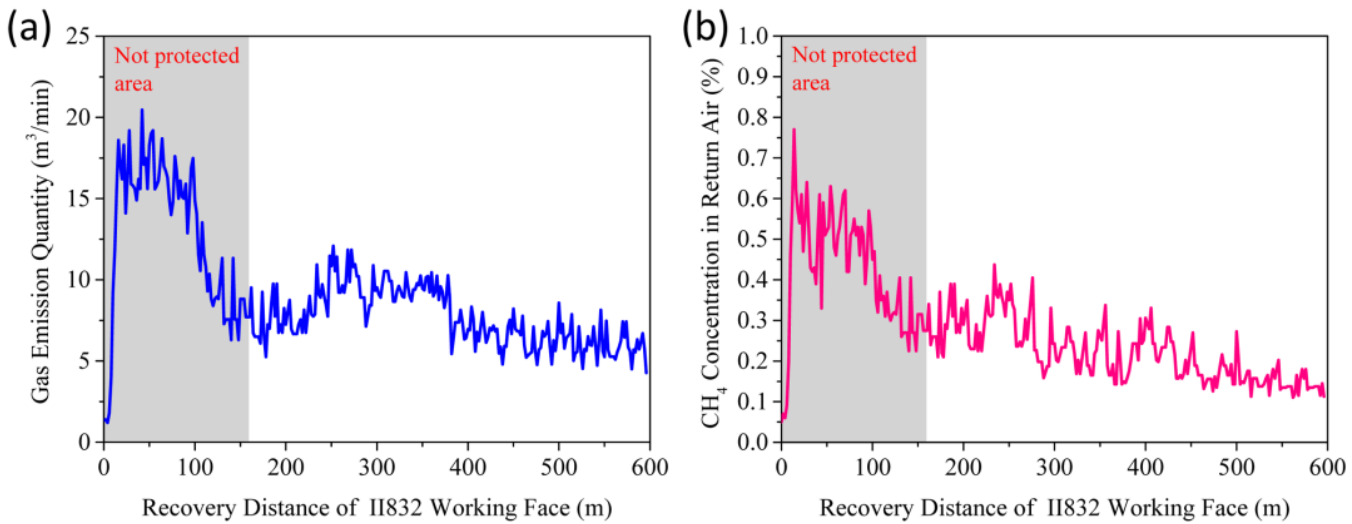

Fig. 13 Gas emission (a) and $\mathrm{CH}_{4}$ concentration in return air (b) during the recovery of the II832 working face. 


\section{Tables}

Table 1 Proximate analyses and adsorption constants of the No. 8 and No. 10 coal seams from the II3 District of the Zhuxianzhuang Coal Mine.

\begin{tabular}{|c|c|c|c|c|c|c|c|c|c|}
\hline \multirow{2}{*}{ Coal seam } & \multicolumn{4}{|c|}{ Proximate analysis (wt.\%) } & \multirow{2}{*}{$\begin{array}{l}\text { True density } \\
\qquad\left(\mathrm{t} / \mathrm{m}^{3}\right)\end{array}$} & \multirow{2}{*}{$\begin{array}{l}\text { Apparent density } \\
\qquad\left(\mathrm{t} / \mathrm{m}^{3}\right)\end{array}$} & \multirow{2}{*}{$\begin{array}{l}\text { Porosity } \\
\text { (\%) }\end{array}$} & \multicolumn{2}{|c|}{ Adsorption constant } \\
\hline & Mois & Ash & VM & FC & & & & $V_{\mathrm{L}}\left(\mathrm{m}^{3} / \mathrm{t}\right)$ & $P_{\mathrm{L}}(\mathrm{MPa})$ \\
\hline No. 8 & 1.91 & 14.12 & 36.56 & 53.44 & 1.37 & 1.28 & 6.57 & 21.3521 & 0.6261 \\
\hline No. 10 & 1.91 & 7.14 & 40.9 & 53.83 & 1.33 & 1.21 & 9.02 & 22.9471 & 0.8875 \\
\hline
\end{tabular}

Mois=moisture; Ash is on a dry basis; $V M=$ =volatile matter, on dry ash free (daf) basis; $F C=f i x e d$ carbon (daf basis).

Data of No. 8 and No. 10 coal seam are average experimental results of 12 and 9 samples obtained from II3 District, Zhuxianzhuang Coal Mine, respectively.

Table 2 Detailed parameters of the protective/protected seams

\begin{tabular}{cccccccc}
\hline \multirow{2}{*}{ Working face } & $\begin{array}{c}\text { Elevation } \\
(\mathrm{m})\end{array}$ & $\begin{array}{c}\text { Length } \\
(\mathrm{m})\end{array}$ & $\begin{array}{c}\text { Width } \\
(\mathrm{m})\end{array}$ & $\begin{array}{c}\text { Average coal thickness } \\
(\mathrm{m})\end{array}$ & $\begin{array}{c}\text { Gas pressure } \\
(\mathrm{MPa})\end{array}$ & $\begin{array}{c}\text { Gas content } \\
\left(\mathrm{m}^{3} / \mathrm{t}\right)\end{array}$ \\
\hline II832 & $-408^{\sim}-483$ & 645 & 125 & 12.42 & 2.4 & 10.03 \\
II1034 & $-475^{\sim}-534$ & 612 & 127 & 2.2 & 0.36 & 4.14 \\
II1036 & $-538^{\sim}-585$ & 660 & 140 & 2.5 & 0.42 & 4.55 \\
\hline
\end{tabular}

Table 3 Coal/rock mass initial properties.

\begin{tabular}{lcccccc}
\hline \multicolumn{1}{c}{ Lithology } & $\begin{array}{c}\text { Density } \\
\left(\mathrm{kg} / \mathrm{m}^{3}\right)\end{array}$ & $\begin{array}{c}\text { Bulk modulus } \\
(\mathrm{GPa})\end{array}$ & $\begin{array}{c}\text { Shear modulus } \\
(\mathrm{GPa})\end{array}$ & $\begin{array}{c}\text { Friction } \\
\text { angle }\left({ }^{\circ}\right)\end{array}$ & $\begin{array}{c}\text { Cohesion } \\
(\mathrm{MPa})\end{array}$ & $\begin{array}{c}\text { Tensile } \\
\text { strength }(\mathrm{MPa})\end{array}$ \\
\hline No. 8 coal seam & 1280 & 1.31 & 0.55 & 25 & 1.22 & 1.45 \\
No. 10 coal seam & 1210 & 1.29 & 0.57 & 25.6 & 1.24 & 1.42 \\
Siltstone & 2630 & 4.30 & 3.36 & 35.6 & 4.38 & 4.56 \\
Aluminum mudstone & 2352 & 2.22 & 1.33 & 30.5 & 1.88 & 1.96 \\
Mudstone & 2461 & 2.17 & 1.02 & 39.4 & 1.64 & 1.54 \\
Sandy mudstone & 2490 & 2.56 & 2.36 & 36 & 2.16 & 2.38 \\
Fine sandstone & 2570 & 4.87 & 2.65 & 35 & 3.62 & 3.58 \\
Medium grained sandstone & 2686 & 5.99 & 3.60 & 37 & 4.01 & 3.97 \\
Medium-fine grained sandstone & 2521 & 2.89 & 2.54 & 29.6 & 3.20 & 3.70 \\
\hline
\end{tabular}

